\title{
Chinese-Foreign Dual Degree Education Programs: Problems and Developments
}

\author{
Xiaoyu Luo ${ }^{1}$ \\ ${ }^{1}$ Hunan University of Technology and Business, China \\ Correspondence: Xiaoyu Luo, Associate Professor, Hunan University of Technology and Business, No.569, Yuelu \\ Road. China. Tel: 0086-180-7320-5888. E-mail: cathyluo1981@gmail.com
}

Received: November 1, 2019; Accepted: November 27, 2019; Published: November 30, 2019

\begin{abstract}
This study researches the current status, problems, and development countermeasures of Chinese-foreign dual degree programs in Chinese higher education by using Microsoft Excel and geographic system information (GIS) software, including their types of degree, geographical distribution, and collaborative partners. The result shows a reasonable reginal distribution of Chinese-foreign dual degree program in higher education is a strong guarantee to promote the coordinated development of higher education. How to establish a common quality guarantee system and make the cooperation certificate-oriented is also need to further research.
\end{abstract}

Keywords: dual degree program, current status, problem and development

\section{Introduction}

Since China joined the World Trade Organization (WTO) and the Chinese government implemented policy of reforms and opening-up, China's economy has rapidly developed with globalization, China's education is also growing in this process of internationalization. More and more cooperative educational programs and cofounded institutions between China and Foreign countries have been established in the past 30 years. Chinese government and policymakers have realized the enhancement of international cooperation and communication will be extremely helpful to improve the quality and level of universities in China. Chinese-foreign cooperative education is inevitable due to fierce international competition of universities and economic globalization.

Chinese-foreign cooperative education has appeared in various forms, including exchange students between universities, dual degree programs, Chinese-foreign joint educational programs, running educational institutions abroad, establishing Confucius institutions and Chinese-foreign cooperatively-run institutions and programs. It is undisputed that Chinese-foreign cooperative education is an important form which adapts to the development of current higher education and strengthens exchange and cooperation in international education.

According to the Statistics website of the Chinese ministry of education (2016), there are currently 2411 ChineseForeign Cooperative Education institutions and programs officially approved in China (Statistics of cooperative education in China, 2016). A considerable number of which are dual degree programs between Chinese and foreign higher education. Since 1995 to 2011, there are 126 programs are approved by Chinese Ministry of Education, the number of dual programs is growing very fast (Statistics of cooperative education in China, 2016).

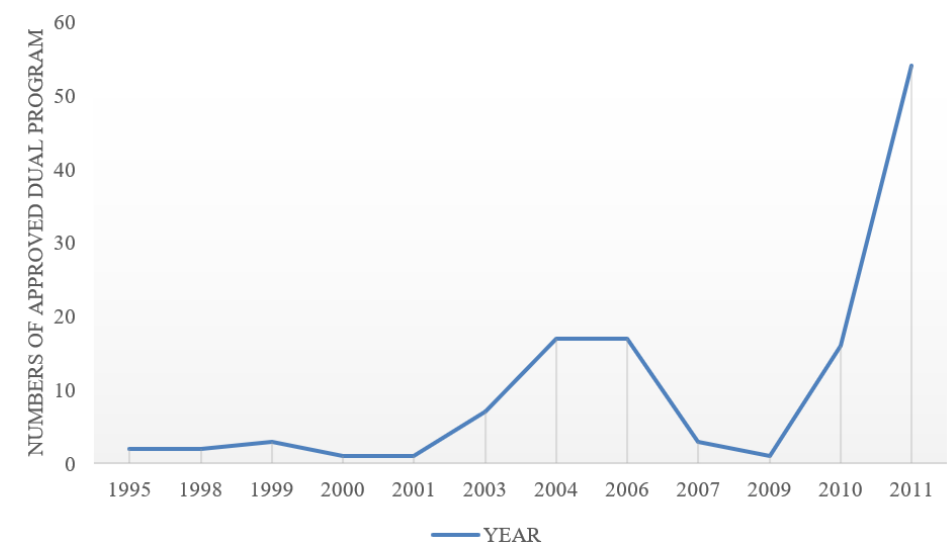

Figure 1. The Developing Trend of Dual Degree Programs in China 
Note: Adapted from "Study of current of double degree programs run jointly by Chinese and foreign higher education," by Zhang, \& Liu, , 2013, Journal of Graduate Education, Vol 5, No.5, P21, in Chinese.

From Figure 1, it is evident that the numbers of dual programs is growing very fast, especially in recent years.

Therefore, this paper will discuss and research the current situation, problems, and development countermeasures of dual degree programs in Chinese higher education by using geographic system information (GIS) software. Dual degree program, also called a double degree program, involves a student can work towards two degrees. It can be a combination of two bachelor's degrees, a bachelor's and a master's degree, or two graduate degrees.

\section{Literature Review}

The first concept of "cooperation running schools" was explicitly put forward in 1993 (Zhang, 2009). In February of that year, the Chinese Communist Party Central Committee and the state council issued the regulation of "Outline for Education Reform and Development in China", which is the first time to propose "international cooperation in running schools within the existing framework of laws and regulations" (State Council, 1993, p.3). In the previous year, Chinese-foreign cooperative education developed rapidly in China, there are different forms of cooperative education institute and program have been emerged in large numbers, especially after joining WTO.

Chinese scholar Tan (1994) first mentioned specific ideas about Chinese-foreign cooperative education in his journal; however, it was a limited introduction of this new type of education new in China. In 1996, Wang and his collages published a specialized paper titled "Pattern research for Chinese-foreign cooperative education". In the authors' paper, the policy of Chinese-foreign cooperative education was described in detail and patterns were outlined. However, the paper briefly discussed some issues without further explanation (Wang, Hu, Wang, \& Wu, 1996). Since then, with the development of Chinese-foreign cooperative education, further journals and articles have been published about this education around the world. The research topics mostly focused on some areas, such as pattern research, challenges and difficulties, development and even police analysis from whole of this education system perspective. For instants, Zhang (2009) analyzed the history of development of policy of Sinoforeign cooperation. Adams and Song (2009) identified the key development in China-foreign cooperation in higher education in terms of policy initiatives and legal frameworks and to highlight the main challenges for the sector in the future.

To be one form of China-foreign cooperation in China, the dual degree program between Chinese and foreign higher education plays an important role. It is found that supranational organizations, national governments, and higher education instructions are the main acting subjects who participate in the development of the dual degree programs (Zhang, 2013). "A double degree program awards two individual qualifications at equivalent levels upon completion of the collaborative program requirements established by the two partner institutions" (Knight, 2011, P135). Knight (2011) provided a microscopic analysis of the doubts and dilemmas with double degree program in last five years using a global perspective. Knight (2011) further highlighted the uncertainty related to quality assurance and qualifications recognition, and referred to ethics involved among operative program. Culver and his colleagues (2012) analyzed the strengths and weakness of dual degree programs at the graduate level in engineering. Lin and Liu (2012) presents the quality construction of Chinese-foreign cooperation in school running, and specifically mentions dual degree programs between Chinese and foreign university in China, but only figured out the policy of assessing quality from administrator perspective. The scholars introduce the international dual degree programs among the different countries and researches the policies of them (Moulton, 2011; Obst, Kuder \& Banks, 2011; Zhang, 2009), some scholars emphasized the quality assurance under the policy (Huang\& Zhang, 2008; Ye, 2012). But most of all are rarely analyzed the dual degree programs between Chinese-foreign higher education in empirical research, especially there is no studies have applied GIS research that. GIS is widely used in applications in different areas but no education field. Such as GIS applications in archaeology (Obst, Kuder, \& Banks. 2011), GIS applications in geotechnical engineering (Singh, Noor, Chitra, Gupta \& Vel, 2015), GIS applications in agriculture (Young, Pierce, \& Clay, 2008), and so on. In additional, GIS applications is used by geographic research and computer application (Amin, Iqbal,, Hussain, Iqbal, \& Saleem, 2016; Chang, \& Park, 2006; Tomic, 2014) It is still in exploring stage in Chinese education.

\section{Research Question}

This paper will research the current situation, problems, and development countermeasures of dual degree programs between Chinese and foreign higher education by using Microsoft Excel and GIS software. Specifically, the following three research questions guided the study: a) Overall, how many Chinese-foreign cooperative education institutes and programs nowadays in China, and how many levels are they in Chinese higher education? 
b) What is the distribution of dual degree programs currently in Chinese higher education and which countries are their partners' countries? And c) whether distribution balance is reasonable or not?

\section{Method}

The purpose of this study was to research the current situation, problems, and development countermeasures of dual degree programs between Chinese and foreign higher education. A descriptive research design was implemented in this study. This chapter contains three sections that will address the research design, methods of study, and the analysis of data. Section One: Research Design provides a description of Chinese-foreign cooperative education in China, especially a description of dual degree programs in Chinese higher education by using Microsoft Excel and GIS software. Section Two: Methods of Study consists of a description of the data sources and the data collection procedures. Section Three: Analysis of Data describes the procedures for testing the statistical analysis of data collected.

\subsection{Research Design}

A descriptive research design, which uses Microsoft Excel and geography system information (GIS) to describe or analyze the current situation, problem and development countermeasures of dual degree programs between Chinese and foreign higher education, was utilized in this study. According to Gall, Borg, and Gall (1996), descriptive research "involves shaping descriptions about educational phenomena" (p.374). This includes not only describing the phenomena, but also providing the development countermeasures.

\subsection{Method of Study}

Data Sources: The data for this study is secondary data which published on the website of Chinese Ministry of Education and literature.

Data collection: Much of this data collection was carried out from the year of annual statement about Chineseforeign cooperative education on the website of Chinese Ministry of Education, a few of the data was from literature review but also was confirmed in the website of Chinese Ministry of Education by manual word account. It has a total of three data tables for this study formatted in Microsoft Excel. The first data table lists distribution of Chinese-foreign dual degree programs in Chinese higher education, which describes the number of dual degree programs among each of provinces in China. The second data table lists distribution of Chinese-foreign cooperative education, which has eight fields for each of provinces in China including the following: the earliest Chinese-foreign cooperative education start year, the numbers of Chinese-foreign cooperative education institutes in undergraduate level, the number of Chinese-foreign cooperative education institutes in undergraduate level with the status of an independent legal entity, the numbers of Chinese-foreign cooperative education institutes in postgraduate level, the numbers of Chinese-foreign cooperative education institutes in postgraduate level with the status of an independent legal entity, the numbers of Chinese-foreign cooperative education programs in undergraduate level, the numbers of Chinese-foreign cooperative education programs in postgraduate level, and the numbers of Chinese universities and colleges involved. The third data table lists the distribution of the numbers and names of partner countries for Chinese-foreign dual degree program.

\subsection{Analysis of Data}

Statistical methods used to interpret the data were descriptive statistics that included characteristics of the data and inferential statistics that included correlation. In order to describe or analyze clearly the current situation, problem and development countermeasures of dual degree programs between Chinese and foreign higher education, data analysis is conducted by using GIS software ArcGIS.

GIS can improve organizational integration, and code information, then, when using GIS software transfer information to data, it reveals relationships of different elements easily. For this study, the forms of patterns and maps for results can visually show the answers of questions and problems. Therefore, this study can provide references for Chinese universities who is going to apply or manage dual degree program, it also can help policy maker in China to make sense the current situation.

\section{Result}

Descriptive Statistical Results.

Figure 2 provides distribution of Chinese-foreign Cooperative institutes in Chinese higher education. 


\section{Chinese-Foreign Cooperative Institutes in Chinese Higher Education}

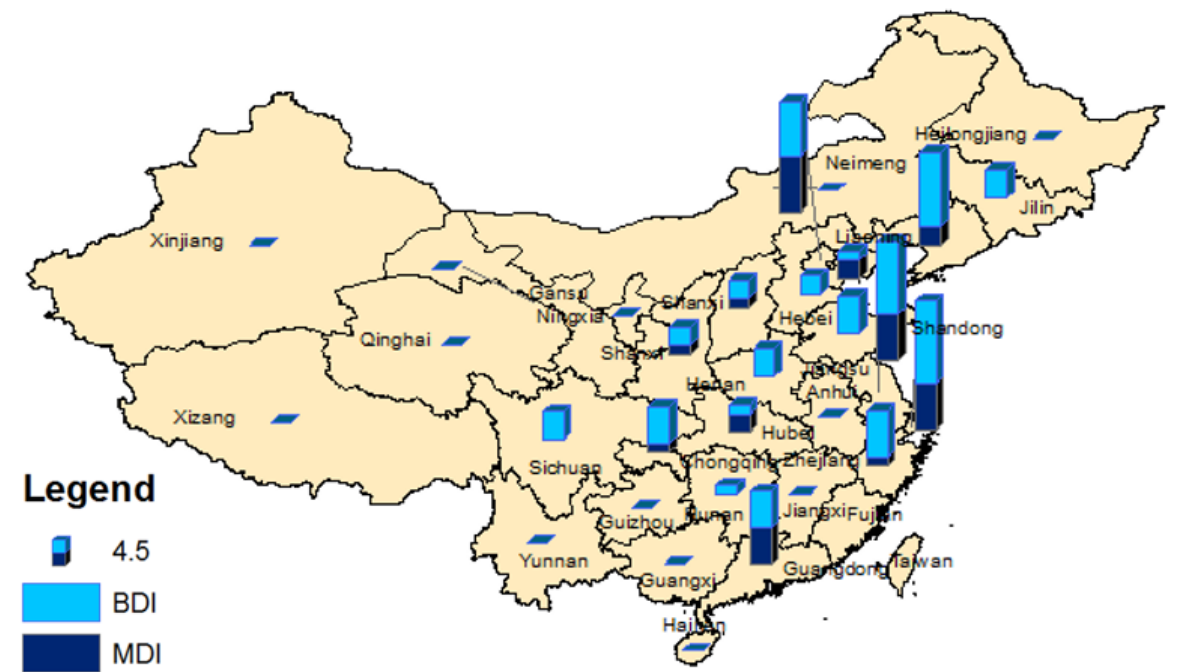

Figure 2. Chinese-Foreign Cooperative Institutes in Chinese Higher Education

Source: Collecting the data of Chinese-foreign cooperative institutes in Chinese higher education according to each provinces and autonomous regions from the website of Chinese Ministry of Education. Adopting from http://www.crs.jsj.edu.cn/index.php/default/index/sort/1006

The result shows that, there are a total of 66 cooperative education institutes at undergraduate level and 29 cooperative education institutes at postgraduate level between Chinese and foreign higher education. The cooperative education institutes are widely distributed in the south, east and north area in China. There are 14 province has no any cooperative education institutes, especially in the west, which included Hainan, Fujian, Jiangxi, Anhui, Heilongjiang, Guangxi, Yunnan, Guizhou, Gansu, Neimeng, Xinjiang, Xizang, Ningxia, Qinghai.

Figure 3 provides distribution of Chinese-foreign Cooperative programs in Chinese higher education.

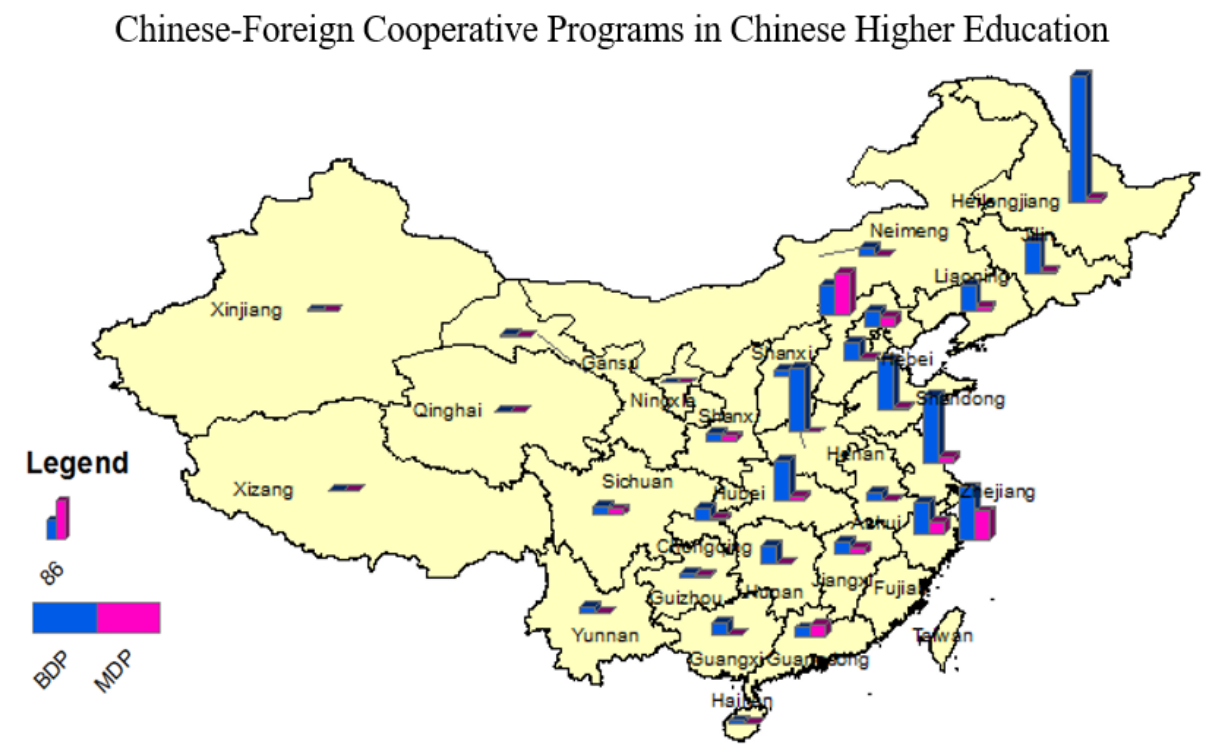

Figure 3. Chinese-Foreign Cooperative Programs in Chinese Higher Education

Source: Collecting the data of Chinese-foreign cooperative programs in Chinese higher education according to each provinces and autonomous regions from the website of Chinese Ministry of Education. Adopting from http://www.crs.jsj.edu.cn/index.php/default/index/sort/1006 
The result shows that, there are a total of 912 cooperative education programs at undergraduate level and 206 cooperative education programs at postgraduate level between Chinese and foreign higher education. The cooperative education institutes are widely distributed in the south, east and north area in China. There are 3 province has no any cooperative education programs, which included Xizang, Ningxia, Qinghai.

As it was mentioned before, Chinese-foreign cooperative education has appeared in various forms, including exchange students between universities, dual degree programs, Chinese-foreign joint educational programs, running educational institutions abroad, establishing Confucius institutions and Chinese-foreign cooperatively-run institutions and programs. This study focuses on dual degree programs, therefore, the Figure 4 presents the distribution of dual degree programs between in China.

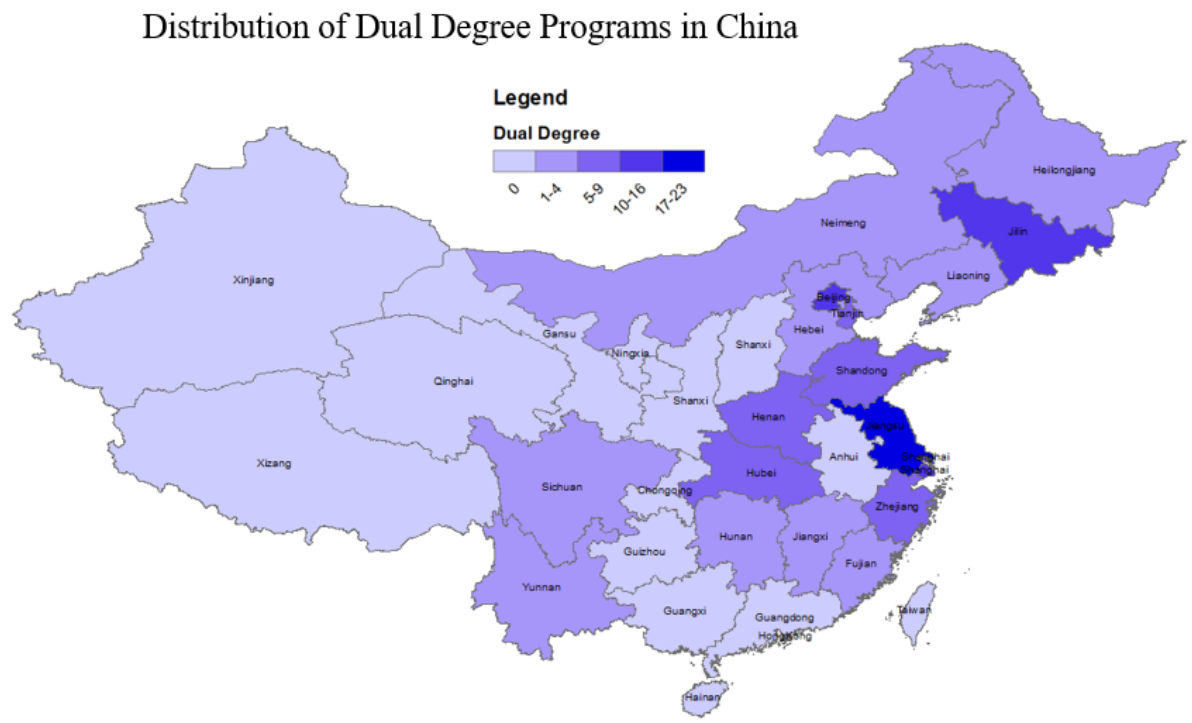

Figure 4. Distribution of Dual Degree Programs between in China

Source: Collecting the data of dual degree programs in China according to each provinces and autonomous regions from the website of Chinese Ministry of Education. Adopting from http://www.crs.jsj.edu.cn/index.php/default/index/sort/1006

The result shows that, there are a total of 88 dual degree programs in Chinese higher education from 20 provinces and municipalities. Most of them distributed in the eastern provinces off the coast and biggest municipalities. Among then, there are 23 dual degree programs in Jiangsu, 16 in Shanghai, 15 in Beijing and 13 in Jilin. There are night provinces without higher education dual degree programs, which includ Xizang, Ningxia, Qinghai, Gansu, Guizhou, Guangxi, Hainan, Anhui, and Chongqing.

Figure 5 presented the distribution of partner countries for Chinese-foreign dual degree program.

Partner Countries for Chinese-Foreign Dual Degree Program All Over the World

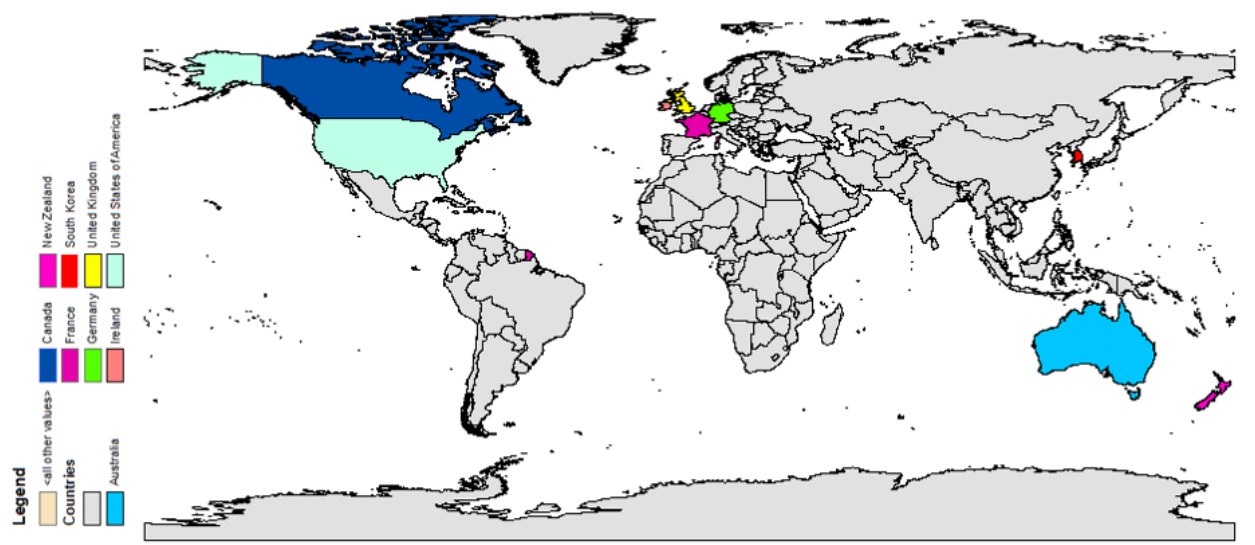

Figure 5. Partner Countries for Chinese-Foreign Dual Degree Program 
Source: Collecting the data of distribution of partner countries for Chinese-foreign dual degree programs all over the world according to each provinces and autonomous regions from the website of Chinese Ministry of Education. Adopting from http://www.crs.jsj.edu.cn/index.php/default/index/sort/1006

The result shows that, there are 9 countries built up the relationship with China for dual degree programs. Most of them are distributed in North America, Europe and Oceania.

Fig. 6 figured out the numbers of partner countries for Chinese-foreign dual degree program.

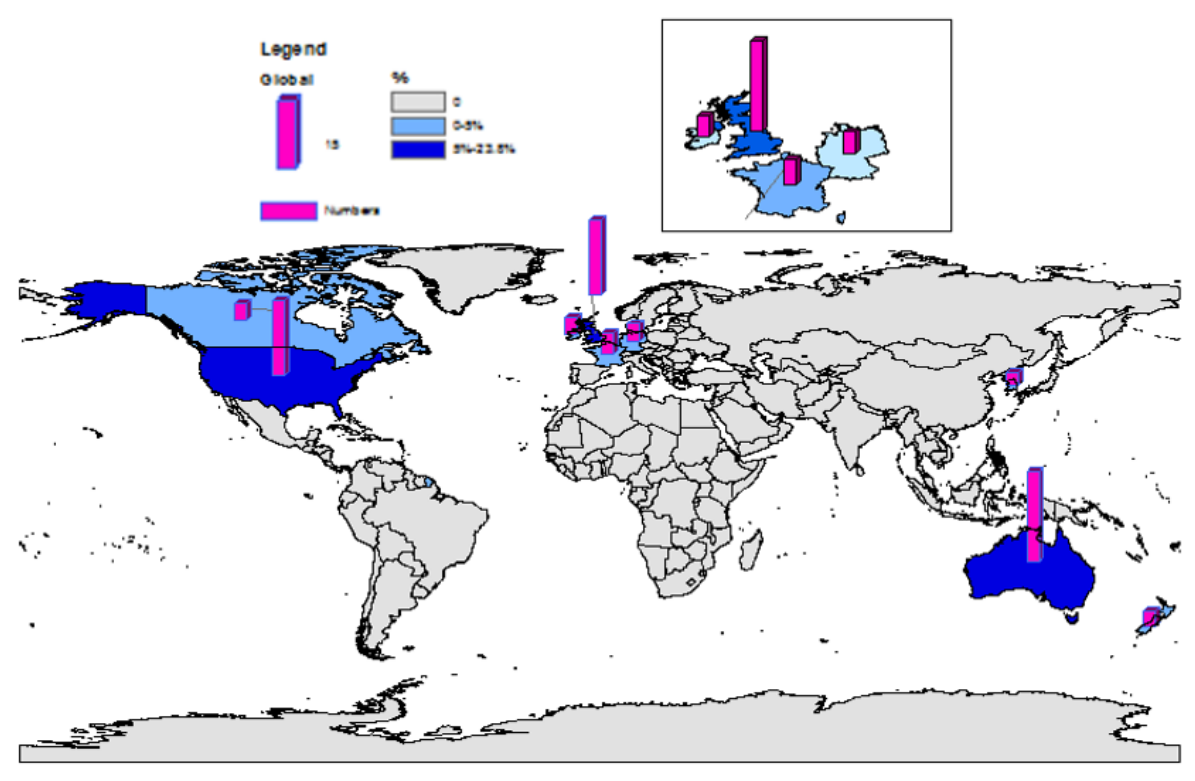

Figure 6. Partner Countries for Chinese-Foreign Dual Degree Program

Source: Collecting the data of the numbers of partner countries for Chinese-foreign dual degree programs all over the world according to each provinces and autonomous regions from the website of Chinese Ministry of Education. Adopting from http://www.crs.jsj.edu.cn/index.php/default/index/sort/1006

The result shows that, from these 9 countries which built up the relationship with China for dual degree programs, the highest numbers of rank 3 for partner countries are Australia, the United States of America, and United Kingdom. The numbers of dual degree programs in these countries are: 30 in Australia, 25 in United States of America, 25 in United Kingdom, 7 in France, 6 in Ireland, 6 in Canada, 6 in Germany, 5 in New Zealand, and 4 in South Korea.

\section{Discussion}

The first research question attempted to determine the current situation of Chinese-foreign cooperative education institutes and programs in China and the also figure out the problem for distribution. The results of figures indicate that there has a significant unbalanced distribution for Chinese-foreign cooperative education institutes and programs both in undergraduate level and in post graduate level. This unbalanced distribution also shows the problem of unbalanced development of Chinese-foreign cooperative education in the economically developed areas and backward areas is very serious in China. According to Zhang (2009), there are some problems in backward areas in China, such as inadequate input funds, sever education debt and unbalanced development. Therefore, that is not only unbalanced development for Chinese-foreign education in China, but also is a problem for unbalanced development of education between economically developed areas and backward areas in China. In the other words, the problem about the unbalanced development of regional higher education has existed for many years since the establishment of higher education in China, that lead to unbalanced development for Chineseforeign cooperative education in China nowadays.

Besides that, the cooperative education between China and foreign countries in higher education focused less on the graduate level and more on undergraduate level. That limitation will influent the development of Chineseforeign cooperative education in China, and also cannot be a long-term basis for fruitful partnerships between Chinese and foreign higher education. 
By influence by Chinese-foreign cooperative education in China, the unbalanced distribution for dual degree program is more prominent. For this reason, it is easy to find out the answer for second research question that the distribution of dual degree program is similar with the distribution of Chinese-foreign cooperative education in China, there is a huge gaps between east and west areas for dual degree program in China from the result shows. Most of them distributed in the eastern provinces off the coast and biggest municipalities. The input of the education finance is not only one element for building up the dual degree program in China, the dual degree program generally have biggish uncertainty, and are always influenced greatly by the police.

The third research question focus on the collaborative partners for dual degree programs in China. The result shows most of the Chinese universities built up the cooperative education with foreign universities, which international dual degree programs distributed mostly in English-speaking countries, such as United Kingdom, United State of America and Australia.

The present study was limited in the following three ways. First, policy in China is subject to change from time to time and may not be announced in advance. That makes dual degree program more difficult to approve by Chinese government. And the collaborative partners also have policies and mechanisms for cooperative education with international dual degree program. For this reason, one the limitation of this study is what policies (both China and foreign countries polices) affect the dual degree program? And how the policies influent the distribution of dual degree programs in China?

Second, besides of policy limitation, the quality of university for both Chinese and partner universities is also a problem for the limitation of this study. From the result of this study, the data only indicated the distribution of the partner's countries, there has no more details for partner universities, such as size of partner universities, education quality of partner universities and so on. From the Fig.3. Chinese-foreign Cooperative programs in Chinese higher education, it is not hard to find out the Chinese-foreign cooperative education is set up more in the undergraduate level, it has less in the graduate level for cooperation. However, with the development of society, it is crying for all-round postgraduates who have a sound academic basis and high quality, adaptable to various jobs and requirements. But the Chinese-foreign dual degree program offers the opportunity to create this advantages. Therefore, it is necessary to further research for the reasons of this phenomenon in order to promote more change to develop cooperative education between China and foreign countries in postgraduate level in high education.

Third, studying the problems for education should be evaluate from different facets, such as instructional practice and curriculum, student learning and so on. The limitation of this study only mentioned the problems existed current status, which focused on the unbalanced distribution of Chinese-foreign dual degree programs in Chinese higher education and low educational level for cooperation.

\section{Conclusion}

The data within the study outlines that Chinese-foreign dual degree program in Chinese higher education is developing rapidly at present. The unbalanced distribution and low educational level for this cooperative program is the bottleneck for the development of higher education finally. Therefore, the development of Chinese-foreign dual degree program in China has shifted from pursuing scale and number expansion to improving quality. Therefore, it is better to manage and control the level, the region and the disciplines of Chinese-foreign dual degree programs in Chinese higher education.

In recent years, there have higher requirement from Chinese universities and also foreign universities for establishing Chinese-foreign dual degree program. Both of Chinese and foreign partners are pursuing the financial achievement and ignored the long-term development for this program. For this reason, it needs to have at the center of any agreement the interests of the students and of the reputation of both Chinese and foreign partner universities. And it also should be changed from student mobility to improving capacity of discipline construction. However, it should regulate and manage the process of cooperation by means of reasonable evaluation for Chinese-foreign dual degree program in higher education.

In conclusion, a reasonable regional distribution of Chinese-foreign dual degree program in higher education is a strong guarantee to promote the coordinated development of higher education. How to establish a common quality guarantee system and make the cooperation certificate-oriented is also needed to further research.

\section{Acknowledgments}

This work was supported by the Hunan Province Education Scientific Research Project Grant XJT(2019)No.291(724), the Hunan Province education scientific research project Grant No. 15B058 and Science Fund of Hunan Province No. 16WLH07. 


\section{References}

Adams, J., \& Song, H. (2009). Key developments and future challenges in China Foreign cooperation in higher education. Journal of Knowledge-Based Innovation in China, 1(3), 185-205. https://doi.org/10.1108/17561410910990575

Amin, R., Iqbal, M. M., Hussain, M., Iqbal, Z., \& Saleem, N. (2016). A cloud based GIS application framework to analyze road accidents using windows azure. International Journal of Computer Science and Information Security, 14(1), 38.

Chang, Y., \& Park, H. (2006). XML web service-based development model for internet GIS applications. International Journal of Geographical Information Science, 20(4), 371-399. https://doi.org/10.1080/13658810600607857

Culver, S. M., Puri, I. K., Spinelli, G., DePauw, K. P. K., \& Dooley, J. E. (2012 \& 2011). Collaborative dual-degree programs and value added for students: Lessons learned through the evaluate-E project. Journal of Studies in International Education, 16(1), 40-61. https://doi.org/10.1177/1028315311403934

Huang, J. R., \& Zhang, C. Y. (2008). Analysis of strategy for transnational education quality assurance in Australia. Higher Education Exploration, 6, 70-73. Chinese Press.

Knight, J. (2011). Doubts and dilemmas with double degree programs. RUSC. Universities and Knowledge Society Journal, 8(2), 135. https://doi.org/10.7238/rusc.v8i2.1067

Lin, J. H., \& Liu, M. G. (2013). On the quality construction of Chinese-foreign cooperation in school running. Educational Research, 10, 72-79. Chinese Press.

Moulton, B. (2011). Double degree: research pathways, enabling cross-disciplinarily and enhancing international competitiveness. Retrieved from http://www.arneia.edu.au/project/39

Obst, K., \& Banks (2011). Joint and double degree programs in the global context: Report on an international survey. Institute of international education. Retrieved from http://www.iie.org/Research-andPublications/Publications-and-Reports/IIE-Bookstore/Joint-Degree-Survey-Report-2011\#.V9v0rXnrsdU

Singh, A., Noor, S., Chitra, R., Gupta, M., \& Vel, N. K. (2015). GIS applications in geotechnical engineering some case studies. International Journal of Latest Trends in Engineering and Technology, 5(2)

State Council. (1993). Outline for Education Reform and Development in China. Beijing: People's Education Press. Chinese Press.

Tan, S. H. (1994). Research on the Development Strategies of Higher Education in China. China Higher Education Research, 2, 24-30. Chinese Press.

Tomic, M. (2014). The use of methods of remote sensing and GIS applications in monitoring water quality on the example of the mining basin. Geonauka, 2(1), 1-8. https://doi.org/10.14438/gn.2013.25

Villa, B., \& Scianna, A. (2011). GIS applications in archaeology. Archeologia e Calcolatori, (22), 337-363.

Wang, P. G., Hu, S. H., Wang, L., \& Wu, S. M. (1996). Pattern research for Chinese-foreign cooperative education. University Education Science, 1, 13-16. Chinese Press.

Ye, L. (2012). Quality assurance of transnational degree program. Zhejiang University Press. Zhejing. In Chinese.

Young, M., Pierce, F. J. D., \& Clay (2008). GIS applications in agriculture. Experimental Agriculture, 44(2), 273. https://doi.org/10.1017/S0014479708006248

Zhang, J. P., \& Liu, S. X. (2013). Study of current of double degree programs run jointly by Chinese and foreign higher education. Journal of Graduate Education, 5, p.21. Chinese Press.

Zhang, J. P. (2013). Research on the transnational double degree programs (Doctoral dissertation). Chinese Press. Retrieved from http://www.cnki.net/KCMS/detail/detail.aspx?QueryID $=2 \&$ CurRec $=1 \&$ recid $=\&$ filename $=$ 1015807883.nh\&dbname $=$ CDFDLAST2016\&dbcode $=$ CDFD $\& p r=\& u r l i d=\& y x=\& v=M z E 0 N j F Y M U x 1 e F 1$ TN0RoMVQzcVRyV00xRnJDVVJMeWZidWRxRkNqblVMek1WRj12Rzd1NEdkbkVySkViUElSOGU

Zhang, M. X. (2009). New era, new policy. Chinese Education \& Society, 42(4), 23-40. https://doi.org/10.2753/CED1061-1932420402

Zhang, X. M. (2009). The construction and operation of Chinese-foreign cooperation in running schools system. Beijing, Higher education press. 


\section{Notes on Contributor}

Xiaoyu Luo is associate professor at Hunan University of Technology and Business, China. She owns her Ph.D. in Niagara University, USA and Master Degree in Brunel University, UK. Her research interests center on English education in higher education, linguistic economics and quantitative research.

\section{Copyrights}

Copyright for this article is retained by the author(s), with first publication rights granted to the journal.

This is an open-access article distributed under the terms and conditions of the Creative Commons Attribution license (http://creativecommons.org/licenses/by/4.0/). 